\title{
Assessment of psychometric properties of the questionnaire on supervisor-doctoral student interaction (QSDI) in Iran
}

\author{
Hooman Daryoushi ${ }^{1}$, Amir Jalali $2^{2^{*}}$, Ehsan Karimi ${ }^{3}$, Nader Salari ${ }^{4}$ and Parvin Abbasi ${ }^{5}$
}

\begin{abstract}
Background: One of the main elements that help students in research projects and composing dissertations is the student-supervisor relationship. A valid and reliable tool to measure this seems essential and it is the objective of the present study to validate and assess the psychometric properties of a questionnaire on supervisor-doctoral student interaction (QSDI) in Iran.

Methods: Before starting the study, a permission from the developer of the tool was secured. Then the tool was forward-backward translated. After preparing the Farsi version of the tool, content validity was confirmed through qualitative and quantitative methods. To examine construct validity, exploratory factor analysis (EFA) and confirmatory factor analysis (CFA) were conducted with participation of 218 and 410 MD, MSc, and PhD students of medical sciences, respectively. To check reliability of the tool, correlation coefficient was used. To examine internal consistency of the tool, Cronbach's alpha was used. Data analyses were done in SPSS (v.25) and LISREL (v.8).

Results: The EFA and CFA results revealed eight factors and 39 items. The value of R-square for the model was equal to 0.99 , which means $99 \%$ of changes in the dependent variable (supervisor-student interaction) is attributed to the independent variable (41 items). That is, $99 \%$ of the dependent variable changes is due to the independent variables. The main indices of the model based on factor analyses were supported $(0.9<)$, which indicated goodness of fit of the model $(X 2 / \mathrm{df}=1.76, \mathrm{CFI}, \mathrm{NFI}, \mathrm{TLI}=0.98 \mathrm{GFI}=0.91$, RMSEA $=0.043$, R-square $=0.99)$. The significance level for correlation coefficient was below 0.05 . Reliability of the tool was supported based on internal correlation (Cronbach's alpha) equal to 0.943 for the whole tool and in 0.89-0.97 range for the subscales.

Conclusion: In general, the results showed that the Farsi version of QSDI (eight factors and 39 items) had acceptable and applicable indices and it can be used as a valid tool in different fields for higher education students of medical sciences.
\end{abstract}

Keywords: Validity, Reliability, Student-supervisor interaction, Persian

\footnotetext{
*Correspondence: jalali_amir@yahoo.com

${ }^{2}$ Substance Abuse Prevention Research Center, Research Institute for Health, Kermanshah University of Medical Sciences, Kermanshah, Iran

Full list of author information is available at the end of the article
} 


\section{Background}

Throughout the course of study, students need educational advices to actualize their potentials and avoid educational problems [1]. The student- supervisors relation is one of the key aspects of higher education programs and research courses in particular [2]. Supervisors might undertake different roles such as a trainer, educator, friend, colleague, role model, and mentor. These roles are fulfilled through trust and mutual relationship between the student and supervisors [3]. An efficient relationship between the student and supervisors leads to a higher educational performance and more efficient learning process [4]. Positive outcomes are expected out of such relationship such as a higher self-confidence, learning motivation, and improvement of professional skills in students, positive learning experience [5], less fear and anxiety in students, lower risk of educational failure, and better provision of support to the student [4].

One of the key responsibilities of higher education students that requires interaction with supervisor is dissertation writing [6]. Composing dissertation is the last stage in MSc and $\mathrm{PhD}$ programs that should be conducted under supervision of an advisor and a supervisor [7]. Success of research projects highly depends on the interaction between the student and supervisors [8]. Therefore, advising professor plays a key role as the guide for the students throughout the program. In the case of an efficient and positive relationship between supervisors and student, the supervisors' role can be fulfilled in the best way possible [9].

A positive relationship between the supervisors and students is featured with respect, trust, and a low level of interpersonal conflicts [10]. Therefore, ability to create an efficient relationship is one of the dominant characteristics of supervisors [11]. Failure to form a decent relationship between supervisors and student leads to problems for the student, instructors, and higher education system in return [3]. Therefore, a proper interaction between the supervisors and student has a notable effect on the quality of dissertation and students' satisfaction [12]. Among the elements of quality of dissertation, some believe that the student-supervisors interaction is one of the most important [3]. This relation is one of the most important factors in the quality of higher education programs [13]. At present, the questionnaires that measure student- supervisors interaction in Iran are researcher-made questionnaires that are designed based on library studies and are not used as a standard questionnaire. Therefore, a standard questionnaire is necessary for conducting related studies in Iran.

There are several tools to examine the interactions between supervisor and students [14-16]. The questionnaire on supervisor-doctoral student interaction (QSDI) by Mainhard is one of these tools. The tool has 41 items designed based on Likert's five-point scale with eight aspects viz. leadership, helping/friendly, understanding, responsibility/freedom, uncertain, dissatisfied, admonishing, and stricture [15]. A short examination of the tool revealed that it perfectly examines the student- supervisors interaction in different fields. Given the absence of a reliable tool for this purpose in Iran, the present study is an attempt to validate and assess psychometric properties of QSDI for MD and higher education students in Iran.

\section{Methods \\ Design}

The study was carried out as a methodological and validation work for cultural validation and psychometric properties assessment of QSDI among MD and higher education students in medical sciences from December 2019 to March 2020.

\section{Participants}

The study population was MD, MSc and $\mathrm{PhD}$ graduates of medical sciences universities over the past 2 years. The participants were selected through convenience sampling and the questionnaires were filled out in presence of researchers or sent to the participants as online copy (via e-mail and social networks).

The sample size for face validity stage consisted of 20 $\mathrm{MD}, \mathrm{MSc}$ and $\mathrm{PhD}$ graduates and in content validity stage consisted of 16 professors. For construct (218 and 410) validity and reliability stage, $410 \mathrm{MD}, \mathrm{PhD}$, and MSc. students of medical sciences were selected. For perform EFA, at first 218 students were selected by convenience sampling methods and then, the samples were increased to 410 students and CFA was performed.

Graduated MD and MSc students over the past 2 years and desire to participate were the inclusion criteria and failure to fill more than $80 \%$ of the content was the exclusion criterion.

\section{Questionnaire on supervisor-doctoral student interaction (QSDI)}

In addition to demographics form, QSDI was used as the tool in the study. The QSDI was introduced by Mainhard et al. in the Netherlands with 41 items. The items are designed based on Likert's five-point scale (never, rarely, sometimes, mostly, and always) and score of each item ranges from 1 to 5 . In the case of direct items, the score " 1 " is assigned to "never" and " 5 " is assigned to always. Some of the items are inversely scored (items No. 2, 3, 4, 5, 7, 10, 11, 14, 15, 16, 18, 20, $21,23,26,29,32,35,37,39$, and 41). The tool has eight subscales and Cronbach's alpha of each item is listed in Table 1 [15]. 
Table 1 QSDI, the sub-scales and Cronbach's alpha

\begin{tabular}{llc}
\hline Dimension & Number of items & Cronbach's alpha \\
\hline Leadership (DC) & 6 & .86 \\
Helping/friendly (CD) & 6 & .87 \\
Uncertain (SO) & 6 & 0.79 \\
Dissatisfied (OS) & 6 & .71 \\
Strict (DO) & 5 & .70 \\
Understanding (CS) & 4 & .75 \\
Student Responsibility/Freedom (SC) & .83 \\
Admonishing (OD) & 4 & .71 \\
\hline
\end{tabular}

\section{Cultural validity}

Translation and cultural validation of the tool was based on Wild's (2005) method [17] so that two Farsi translations of the tool were prepared by two native Farsi speakers and the translations were examined by the research team members. The two translations were merged and one copy was developed. Two other translators translated the Farsi version into English separately. The two English copies were examined, which is one of the main steps of cultural adaptation process. The translations were compared to the original version to spot difference and ensure conceptual similarity to the original copy. Eventually, the final copy was sent to the developer of the tool for confirmation.

To check cognitive similarity, the final copy was provided to $20 \mathrm{MD}$ and MSc graduates in medical sciences to examine their perception, interpretation, and understanding of the translated copy. The tool was revised based on the results of cognitive information to ensure cultural comparability. Then, grammatical or spelling errors were checked and the final scale was prepared.

\section{Analysis}

\section{Descriptive analysis}

Demographic variables of the research units were examined using relative frequency and content, mean and standard deviations of the mode.

\section{Face validity}

To check face validity, the scale was provided to another $20 \mathrm{PhD}$ and MSc. graduates in medical sciences and in face-to-face interviews they were asked to highlight any vague item and word or ambiguity or wrong perception in the text.

\section{Content validity}

As to content validity, the tool was provided to 16 researchers, members of faculty boards, and experts of this subject from different disciplines. Their feedbacks were used to revise the scale and through this, content validity was ensured qualitatively. To determine content validity through quantitative method, content validity index (CVI) was obtained based on Walts and Bassel index [18] for each item (Table 2).

\section{Construct validity}

To check construct validity, exploratory factor analysis (EFA) and confirmatory factor analysis (CFA) were used.

In each stage of EFA and CFA, normal distribution of the data was checked using multivariate test.

In each stage of EFA and CFA, normal distribution of the data was checked using multivariate test. Because CFA with the maximum likelihood method is based on the assumption of normal distribution of data, the normal distribution of one and also multivariate data was examined. Skewness value for each statement varied from -1.42 to 0.55 and it was at $(-2,2)$ range. This means that, the statements are normal in terms of skewness with symmetric distribution [19]. Moreover, Kurtosis ranged from -1.15 to 1.5 (Table 2). To discuss multivariate normality (Mardia test), if the critical ratio (cr) (Mardia test) for kurtosis is less than seven, the multivariate normality is rejected. In this study, the critical ratio (cr) (Mardia test) was 149.357, which was greater than seven and the normal distribution was supported $[19,20]$.

In addition, given factor load of each item (for tvalue $>1.96, p$-value $=95 \%$; for $\mathrm{t}$-value $>2.576, p$-value $=$ $\% 99$; and for $\mathrm{t}$-value $>3.29, p$-value $=\% 999$ ), to examine goodness of fit of the model, maximum likelihood method was used. To check reliability of the scores, internal consistency method was used through computing Cronbach's alpha for each item and the whole tool.

\section{Results}

\section{Descriptive results}

In the case of EFA, totally, $57.3 \%$ of the participants were female and $42.7 \%$ were male. The mean age of 218 participants was $30.4 \pm 6$ with minimum and maximum ages equal to 24 and 51 years respectively. The mean time duration of preparing the dissertation from the approval of proposal to approval of the final 
Table 2 The ratio and index of content validity Skewness and Kurtosis of the tool items

\begin{tabular}{|c|c|c|c|c|c|c|c|}
\hline \multirow[t]{2}{*}{ No } & \multirow{2}{*}{$\begin{array}{l}\text { Items } \\
\text { My supervisor... }\end{array}$} & \multirow[t]{2}{*}{$\mathrm{CVR}^{\mathrm{a}}$} & \multirow[t]{2}{*}{$\mathrm{CVI}^{\mathrm{b}}$} & \multicolumn{2}{|c|}{ Skew $^{c}$} & \multicolumn{2}{|l|}{ Kurt $^{\text {d }}$} \\
\hline & & & & & cr & & cr \\
\hline 1 & always cooperates, if I want something & .67 & .92 & .13 & 1.05 & -.26 & -1.1 \\
\hline 2 & humiliates me & .83 & .92 & .21 & 1.74 & -.75 & -3.1 \\
\hline 3 & acts unconvincingly regarding my initiatives & .83 & .83 & -.35 & -2.86 & -.45 & -1.86 \\
\hline 4 & is quick to criticize me & .83 & .92 & -.07 & -.54 & -.66 & -2.7 \\
\hline 5 & is unclear during our conversations & .67 & .92 & -.32 & -2.59 & -.27 & -1.1 \\
\hline 6 & trusts me & .83 & .83 & -.57 & -4.68 & .06 & .26 \\
\hline 7 & disbelieves me & .50 & .92 & -1.2 & -10.2 & 1.46 & 6.1 \\
\hline 8 & helps me & .67 & .92 & -.02 & -.2 & -.61 & -2.5 \\
\hline 9 & gives thorough feedback on my work & .83 & .83 & .02 & .13 & -.6 & -2.48 \\
\hline 10 & has a bad temper during our discussions & .67 & .92 & -.62 & -5.14 & -.34 & -1.38 \\
\hline 11 & is dissatisfied about my progress & .83 & .92 & -1.42 & -11.7 & 1.5 & 6.3 \\
\hline 12 & follows my proposals & .50 & .83 & .15 & 1.2 & -.78 & -3.2 \\
\hline 13 & anticipates possible misunderstandings between us & .67 & .92 & .55 & 4.53 & -.27 & -1.12 \\
\hline 14 & thinks I know nothing & .83 & .92 & -.78 & -6.4 & -.34 & -1.4 \\
\hline 15 & is impatient towards me & .67 & .83 & -.67 & -5.56 & -.3 & -1.26 \\
\hline 16 & is critical of my work & .67 & .75 & .05 & .37 & .05 & .2 \\
\hline 17 & listens to me & .83 & .92 & .14 & 1.1 & -.99 & -4.1 \\
\hline 18 & creates an atmosphere of ambiguity during our meeting & .67 & .83 & -.32 & -2.7 & -.65 & -2.7 \\
\hline 19 & is strict when evaluating my progress & .83 & .75 & .28 & 2.3 & -.07 & -.3 \\
\hline 20 & demands a lot from me & .67 & .83 & -.05 & -.39 & -.64 & -2.66 \\
\hline 21 & acts confidently when discussing my papers & .67 & .92 & .05 & .44 & -.24 & -1.08 \\
\hline 22 & says that I am unskilled & .50 & .83 & .21 & 1.3 & -.26 & -1.1 \\
\hline 23 & always explains comprehensibly when I ask something & .50 & .92 & -.24 & -2.02 & -.09 & -.36 \\
\hline 24 & gives me clear guidance & .67 & .83 & -.15 & -1.2 & .12 & .49 \\
\hline 25 & thinks that I am dishonest & .50 & .92 & .18 & 1.25 & -.15 & -2.1 \\
\hline 26 & supports me & .67 & .92 & .27 & 2.22 & -.71 & -2.92 \\
\hline 27 & gives me a lot of advice & .67 & .83 & .36 & 2.95 & -.29 & -1.2 \\
\hline 28 & is indecisive about my initiatives & .83 & .92 & -.48 & -3.99 & .04 & .18 \\
\hline 29 & acts professionally during our meetings & .83 & .92 & -.18 & -1.5 & -.08 & -.32 \\
\hline 30 & reacts enthusiastically about my initiatives & .83 & .83 & .44 & 3.67 & -.95 & -3.91 \\
\hline 31 & acts irritable with me & .83 & .92 & .36 & 3 & -.7 & -2.88 \\
\hline 32 & is someone I can rely on & .67 & .83 & -.1 & -.86 & -.5 & -2.04 \\
\hline 33 & pays attention, if I have something to say & .67 & .75 & .11 & .92 & -.75 & -3.1 \\
\hline 34 & is uncertain during our meetings & .50 & .83 & -.3 & -2.48 & -.23 & -.95 \\
\hline 35 & allows me to make my own decisions & .50 & .92 & .2 & 1.68 & -1.15 & -4.77 \\
\hline 36 & believes that I am untrustworthy & .67 & .83 & -.65 & -5.38 & 0.29 & 1.2 \\
\hline 37 & shares my sense of humor & .83 & .83 & .06 & .47 & -.83 & -3.44 \\
\hline 38 & is timid in our discussions & .67 & .75 & .19 & 1.6 & -.52 & -2.14 \\
\hline 39 & let's me choose my own direction & .67 & .83 & -.82 & -6.8 & .56 & 2.3 \\
\hline 40 & is easily impressed by me & .50 & .92 & .04 & .36 & -.89 & -3.67 \\
\hline \multirow[t]{2}{*}{41} & immediately corrects me if I do something wrong & .83 & .83 & .36 & 2.94 & .31 & 1.3 \\
\hline & Multivariate (Mardia test) & & & & & 834.27 & 149.36 \\
\hline
\end{tabular}


Table 3 Demographic characters of participants in study

\begin{tabular}{|c|c|c|c|}
\hline Variables & & $\begin{array}{r}\text { EFA } \\
\mathrm{N}(\%) \\
\end{array}$ & \multirow{2}{*}{$\begin{array}{l}\text { CFA } \\
\text { N (\%) }\end{array}$} \\
\hline \multirow{3}{*}{ Gender } & & & \\
\hline & Male & $93(42.7)$ & $180(43.9)$ \\
\hline & Female & $125(57.3)$ & $230(56.1)$ \\
\hline \multirow[t]{2}{*}{ Residence Location } & Family house & $129(59.2)$ & $261(63.7)$ \\
\hline & Student dormitory & $89(40.8)$ & 149 (36.3) \\
\hline \multirow[t]{3}{*}{ Course grade } & $M D$ & $114(52.3)$ & $217(52.9)$ \\
\hline & MSc & 79 (36.2) & $152(37.1)$ \\
\hline & $\mathrm{PhD}$ & $25(11.5)$ & $41(10)$ \\
\hline \multirow[t]{5}{*}{ Field of Study } & Medicine & $104(47.7)$ & $204(49.8)$ \\
\hline & Pharmacy & $12(5.5)$ & $18(4.4)$ \\
\hline & Dentistry & $17(7.8)$ & $29(7.1)$ \\
\hline & Nursing \& Midwifery & $63(28.9)$ & $117(28.5)$ \\
\hline & Health & $22(10.1)$ & $42(10.2)$ \\
\hline \multirow[t]{2}{*}{ Supervisor gender } & Male & $53(24.3)$ & $84(69.3)$ \\
\hline & Female & $165(75.7)$ & $126(60.7)$ \\
\hline \multirow[t]{4}{*}{ Supervisor degree } & Lecturer & $13(6)$ & $21(5.1)$ \\
\hline & Assistant Professor & $101(46.3)$ & $191(46.6)$ \\
\hline & Associate Professor & $77(35.3)$ & $159(38.8)$ \\
\hline & Professor & $27(12.4)$ & $39(9.5)$ \\
\hline
\end{tabular}

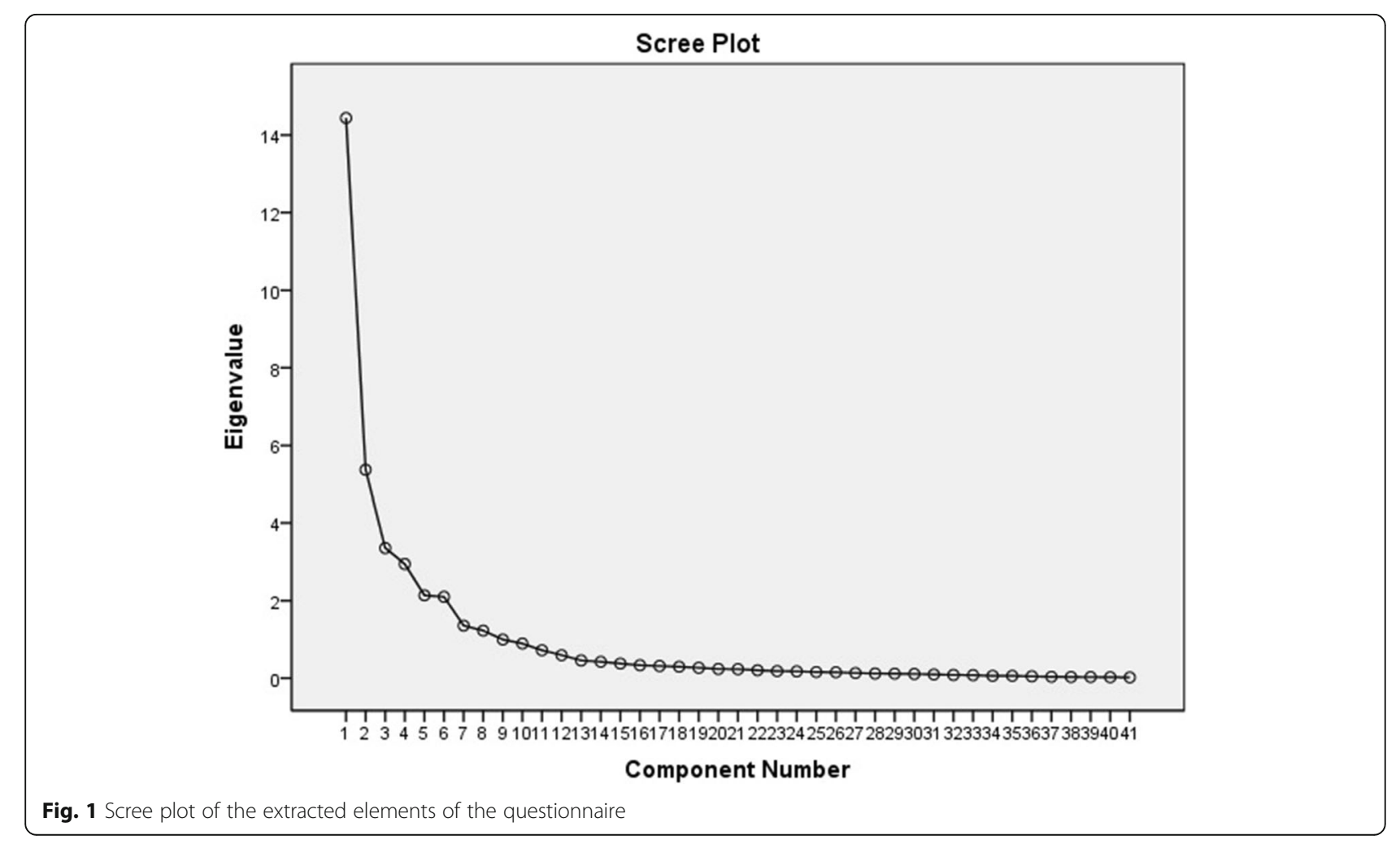

Fig. 1 Scree plot of the extracted elements of the questionnaire dissertation was $16.2 \pm 8.1$ months ( $\min =6$ months; $\max =48$ months).

In the case of CFA, totally, $56.1 \%$ of the participants were female and $43.9 \%$ were male. The mean age of 410 participants was $30.22 \pm 5.92$ with minimum and maximum ages equal to 24 and 51 years respectively. The mean time duration of preparing the dissertation from the approval of proposal to approval of the final dissertation was $16.14 \pm 7.9$ months $(\min =6$ months; $\max =48$ months). See Table 3 for the rest of demographics.

\section{Construct validity results}

Before EFA, correlation of coefficient between the items was checked. Kaiser-Meyer-Olkin (KMO) test was obtained equal to 0.829 and Bartlett's test of sphericity $\left(x^{2}=10,932.91\right.$, sig $\left.=0.0001\right)$ based on KMO test $(0.7<)$ supported adequacy of correlation in the data. Moreover, $p$-value of Bartlett's test was less than 0.05. Therefore, the required conditions for KMO were met. Principle components (PC) and Varimax Rotation were used for extracting the factors.

Communality value of all items was higher than 0.5. Therefore, none of the items were deleted in this stage and the rest of analyses were done on the 41 items.

To determine the number of factors, those with eigenvalue percentage higher than 1 were selected. The primary findings showed that eight factors can be selected for analysis. Additional file 1: Annexed Table 1. lists the 
Table 4 Results of CFA and reliability and consistency coefficients of sub-scale of measurement of QSDI

\begin{tabular}{|c|c|c|c|c|c|c|c|}
\hline \multicolumn{2}{|l|}{ Factors } & \multirow{2}{*}{$\begin{array}{l}\text { Items } \\
\text { My supervisor }\end{array}$} & \multirow[t]{2}{*}{ Mead(sd) } & \multirow[t]{2}{*}{$\mathrm{T}(\mathrm{cr})^{\mathrm{a}}$} & \multirow[t]{2}{*}{$\lambda^{\mathrm{b}}$} & \multicolumn{2}{|c|}{ Cronbach's alpha } \\
\hline & & & & & & Items & Factors \\
\hline \multirow[t]{5}{*}{ CD } & 1 & always cooperates, if I want something & 4.32(.92) & 15.83 & .71 & .87 & .893 \\
\hline & 8 & helps me & $4.3(.88)$ & 14.94 & .68 & .83 & \\
\hline & 13 & anticipates possible misunderstandings between us & $3.94(1.22)$ & 8.06 & .40 & .67 & \\
\hline & 26 & supports me & 4.45(.79) & 12.7 & .60 & .59 & \\
\hline & 30 & reacts enthusiastically about my initiatives & 4.28(.93) & 12.7 & .60 & .81 & \\
\hline \multirow[t]{5}{*}{ OD } & 2 & humiliates me & 4.72(.68) & 14.14 & .65 & .93 & .936 \\
\hline & 10 & has a bad temper during our discussions & 4.65(.72) & 13.92 & .64 & .91 & \\
\hline & 15 & is impatient towards me & 4.65(.74) & 14.59 & .66 & .92 & \\
\hline & 31 & acts irritable with me & $4.56(.8)$ & 11.13 & .53 & .93 & \\
\hline & 32 & is someone I can rely on & 4.68(.74) & 13.47 & .62 & .92 & \\
\hline \multirow[t]{6}{*}{ SO } & 3 & acts unconvincingly regarding my initiatives & $3.74(1.35)$ & 13.57 & .62 & .95 & .959 \\
\hline & 5 & is unclear during our conversations & $3.69(1.35)$ & 12.42 & .58 & .95 & \\
\hline & 18 & creates an atmosphere of ambiguity during our meeting & $3.69(1.34)$ & 13.78 & .63 & .95 & \\
\hline & 28 & is indecisive about my initiatives & $3.29(1.39)$ & 0.13 & .01 & .97 & \\
\hline & 34 & is uncertain during our meetings & $3.7(1.32)$ & 13.19 & .61 & .94 & \\
\hline & 38 & is timid in our discussions & $3.59(1.39)$ & 2.7 & .14 & .96 & \\
\hline \multirow[t]{5}{*}{ DO } & 4 & is quick to criticize me & $3.91(1.06)$ & 8.15 & .40 & .84 & .894 \\
\hline & 16 & is critical of my work & 3.99(.98) & 9.03 & .44 & .91 & \\
\hline & 19 & is strict when evaluating my progress & $4.05(1.05)$ & 13.00 & .63 & .87 & \\
\hline & 20 & demands a lot from me & $3.73(1.13)$ & -0.41 & -.02 & .87 & \\
\hline & 41 & immediately corrects me if I do something wrong & $3.85(1.09)$ & 9.12 & .45 & .86 & \\
\hline \multirow[t]{4}{*}{ CS } & 6 & trusts me & 4.35(.94) & 12.51 & .59 & .91 & .932 \\
\hline & 17 & listens to me & 4.32(.97) & 15.53 & .70 & .9 & \\
\hline & 33 & pays attention, if I have something to say & $4.22(1.03)$ & 12.17 & .57 & .91 & \\
\hline & 37 & shares my sense of humor & $4.08(1.11)$ & 11.11 & .53 & .93 & \\
\hline \multirow[t]{6}{*}{ OS } & 7 & disbelieves me & $4.32(1.05)$ & 11.01 & .52 & .97 & .97 \\
\hline & 11 & is dissatisfied about my progress & $4.32(1.04)$ & 12.47 & .58 & .96 & \\
\hline & 14 & thinks I know nothing & $4.3(1.02)$ & 13.53 & .62 & .96 & \\
\hline & 22 & says that I am unskilled & $4.35(1.02)$ & 10.67 & .50 & .968 & \\
\hline & 25 & thinks that I am dishonest & $4.33(1.02)$ & 13.28 & .61 & .964 & \\
\hline & 36 & believes that I am untrustworthy & $4.34(1.02)$ & 10.47 & .50 & .964 & \\
\hline \multirow[t]{6}{*}{ DC } & 9 & gives thorough feedback on my work & $4.18(1.04)$ & 12.03 & .56 & .91 & .93 \\
\hline & 21 & acts confidently when discussing my papers & $3.78(1.26)$ & 5.5 & .27 & .94 & \\
\hline & 23 & always explains comprehensibly when I ask something & $4.27(1.02)$ & 12.59 & .59 & .91 & \\
\hline & 24 & gives me clear guidance & $4.12(1.06)$ & 9.82 & .47 & .92 & \\
\hline & 27 & gives me a lot of advice & 4.25(.98) & 13.45 & .62 & .91 & \\
\hline & 29 & acts professionally during our meetings & 4.1491.02) & 10.95 & .52 & .91 & \\
\hline \multirow[t]{5}{*}{ SC } & 12 & follows my proposals & 4.09(.94) & 11.7 & .55 & .89 & .932 \\
\hline & 35 & allows me to make my own decisions & 4.22(.99) & 12.63 & .59 & .87 & \\
\hline & 39 & let's me choose my own direction & 4.08(.999) & 11.36 & .54 & .86 & \\
\hline & 40 & is easily impressed by me & $4.04(1.02)$ & 8.81 & .42 & .89 & \\
\hline & & QSDI (39 items) & & & & & .943 \\
\hline
\end{tabular}

${ }^{\mathrm{a}}$ The calculated values of $\mathrm{t}$ for all factor loads of the first and second order are greater than 1.96 and are therefore significant at the $95 \%$ confidence level, ${ }^{\mathrm{b}}$ The specific value, which is denoted by the Landa coefficient and the statistical symbol $\lambda$, is calculated from the sum of the factors of the factor loads related to all the variables of that factor 


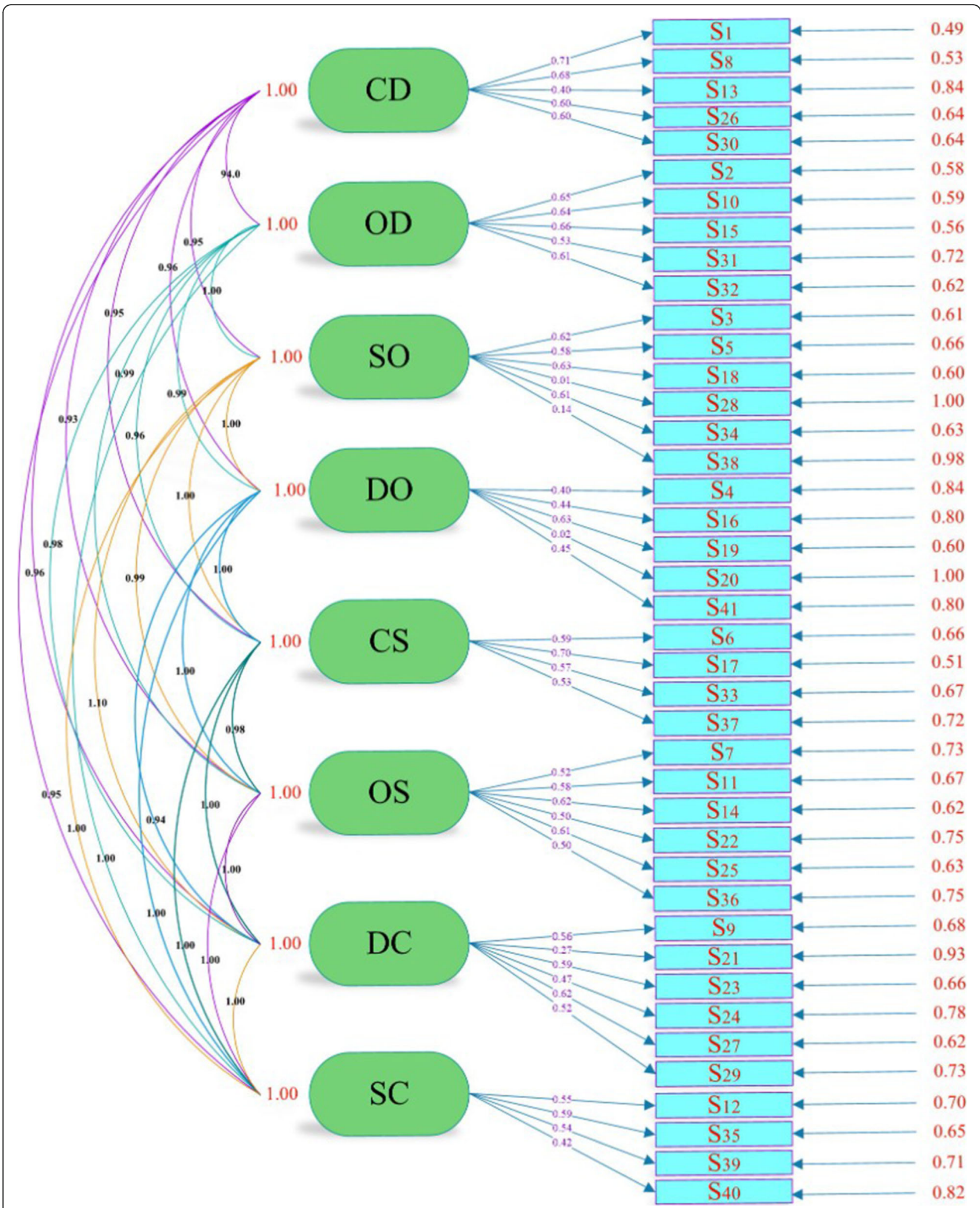

Fig. 2 Eight factor model of CVI in QSDI in Iranian students- Standard 
Table 5 Fit indicators confirmatory factor analysis persian version of QSDI

\begin{tabular}{lll}
\hline Fit indicators & Criterion & Level \\
\hline$X^{2} / D F$ & $3 \geq$ & 1.76 \\
CFI & $9 .<$ & .98 \\
NNFI/TLI & $9 .<$ & .98 \\
GFI & $9 .<$ & .91 \\
RMSEA & $05 .>$ & .043 \\
R-square & & .99 \\
SRMR & $05 .>$ & .045 \\
df & & 751 \\
Chi-Square & & 1323.55 \\
Pvalue & & 1.00 \\
\hline
\end{tabular}

factors extracted along with the eigenvalue, share of each factor in the variance of 41 items, and accumulated variance by each nine items.

Totally, $80.34 \%$ of the variance of 41 items can be attributed to the eight items with eigenvalue $>1$. The scree plot showed that the nine factors can be used for final analysis (Additional file 1: Annexed Table 2 and Fig. 1).

The CFA was conducted on eight factors and 41 items. Table 4. and Fig. 2. illustrate the results of CFA in standard coefficient modes.

Since $t$-values of items no. 20 and 28 were less than 1.96, these two items were omitted (Table 4). Table 5 lists goodness of fit indices of CFA, which supports fitness of the model with the obtained data.

Table 5 lists the final results of EFA and CFA, which were completed with eight factors and 39 items. Pearson correlation test indicated a positive and significant correlation $(p<0.001)$ between QSDI subscales and the whole scale (Table 6).

\section{Internal and external validity results}

To check internal reliability, Cronbach's alpha was obtained for the scale equal to 0.943 . In the case of subscales, Cronbach's alpha was between 0.89 and 0.97 so that the subscales have the required reliability (Table 6). All of reliability coefficients of the factors and the questionnaire itself were at the desired level.

As listed in Table 6, there is a positive and significant correlation between QSDI and all of factors (subscales) and also between the factors. In general, at the end of the two stages (EFA and CFA) and after removing items No. 20 and 28 (in the CFA method), eight factors and 39 items were extracted as described in the Table 6.

\section{Discussion}

Cultural validation and psychometrics of Farsi version of QSDI for PhD and MSc students in medical science universities in Iran were examined. After obtaining content validity through qualitative method, content validity was obtained through quantitative method as a supplementary measure. To this end, CVR and CVI were obtained

Table 6 Correlation coefficients of scale factors together and with the whole scale

\begin{tabular}{|c|c|c|c|c|c|c|c|c|c|c|}
\hline & & DC & $C D$ & DO & So & CS & OS & SC & $O D$ & QSDI \\
\hline \multirow[t]{2}{*}{$D C$} & $\mathrm{R}$ & 1 & & & & & & & & \\
\hline & Sig. & & & & & & & & & \\
\hline \multirow[t]{2}{*}{$C D$} & $\mathrm{R}$ & $.686^{* *}$ & 1 & & & & & & & \\
\hline & Sig. & .03 & & & & & & & & \\
\hline \multirow[t]{2}{*}{ DO } & $\mathrm{R}$ & $.632^{* *}$ & $.66^{* *}$ & 1 & & & & & & \\
\hline & Sig. & .000 & .000 & & & & & & & \\
\hline \multirow[t]{2}{*}{ SO } & $\mathrm{R}$ & $.721^{* *}$ & $.693^{* *}$ & $.673^{* *}$ & 1 & & & & & \\
\hline & Sig. & .000 & .000 & .000 & & & & & & \\
\hline \multirow[t]{2}{*}{ CS } & $\mathrm{R}$ & $.573^{* *}$ & $.611^{* *}$ & $.567^{* *}$ & $.656^{* *}$ & 1 & & & & \\
\hline & Sig. & .000 & .000 & .000 & .000 & & & & & \\
\hline \multirow[t]{2}{*}{ OS } & $\mathrm{R}$ & $.685^{* *}$ & $.982^{* *}$ & $.661^{* *}$ & $.688^{* *}$ & $.638^{* *}$ & 1 & & & \\
\hline & Sig. & .000 & .000 & .000 & .000 & .000 & & & & \\
\hline \multirow[t]{2}{*}{ SC } & $\mathrm{R}$ & $.647^{* *}$ & $.642^{* *}$ & $.653^{* *}$ & $.735^{* *}$ & $.625^{* *}$ & $.666^{* *}$ & 1 & & \\
\hline & Sig. & .000 & .000 & .000 & .000 & .000 & .000 & & & \\
\hline \multirow[t]{2}{*}{$\mathrm{OD}$} & $\mathrm{R}$ & $.683^{* *}$ & $.707^{* *}$ & $.707^{* *}$ & .733 & .636 & $.694^{* *}$ & .692 & 1 & \\
\hline & Sig. & .000 & .000 & .000 & .000 & .000 & .000 & .772 & & \\
\hline \multirow[t]{2}{*}{ QSDI } & $\mathrm{R}$ & $.846^{* *}$ & $.748^{* *}$ & $.728^{* *}$ & $.884^{* *}$ & $.776^{* *}$ & $.844^{* *}$ & $.833^{* *}$ & $.872^{* *}$ & 1 \\
\hline & Sig. & .000 & .000 & .000 & .000 & .000 & .000 & .000 & .000 & \\
\hline
\end{tabular}

** $P<.01$ 
and content validity of the tool was supported. This indicated good cultural validity of the scale for Iranian society.

The EFA and CFA were used for construct validity. Reliability and internal validity of the scale were checked using Cronbach's alpha and the correlation coefficients among the factors respectively. The EFA results confirmed the scale with eight factors and 41 items, the original tool has eight factors and 41 items [15]. To measure construct validity of student-supervisor relationship scale, Ali et al. (2016) used EFA [21]. Castello et al. used EFA to check construct validity of the tool. Based on the EFA results, some of the subscales were removed [22, 23]. To elaborate on the findings, in addition to the effect of culture and educational structure on respondents' answers, it is notable that the developer of the scale has not examined construct validity of the tool. The present study, however, used EFA as a key measure of construct validity of the scale $[24,25]$.

The results of CFA confirmed the scale with eight factors and 39 items (CFI > 0.9; NNFI, GFI $>0.8$, and RMSE $A=0.043)$. The original scale has eight factors and 41 items [15]. Removal of two items from the original scale based on EFA and CFA results can be explained by the different research environment, Iranian culture, and number of participants.

The results showed that the 39-item scale obtained through factor analysis two items eliminated in CFA) has a positive and significant correlation with its eight subscales. In addition, the results supported internal stability of the scale and Cronbach's alpha for the 39-item scale was equal to 0.96. Cronbach's alphas of leadership, helping/friendly, understanding, responsibility/freedom, uncertain, dissatisfied, admonishing, and strict were equal to $0.93,0.893,0.932,0.91,0.959,0.97,0.936$, and 0.894 respectively; these figures in Minhard's et al. study were $0.71,0.73,0.75,0.7,0.71,0.79,0.87$, and 0.86 respectively [15]. Clearly, the eight factors in the present study are consistent with Mainhard's et al., which can be explained based on cultural differences, participants' difference, and number of participants.

Minhard et al. reported that there was an inverse correlation between $\mathrm{SO}, \mathrm{OS}$, and $\mathrm{OD}$ and $\mathrm{Dc}, \mathrm{CD}, \mathrm{CS}$, and SC. In addition, the correlation between DO and CS, SC, and SO was direct [15]. The present study, however, showed that the positive and significant correlation between all factors.

Consistent with the results of the initial study [15], the model has eight axes and each of which can have a significant impact on the model. In Minhard et al., DCleadership, CD-helping / friendly, CS-understanding, and SC-student responsibility / freedom had a higher degree of proximity than the other four axes. In terms of influences, the OD-admonishing, DO-strict, DC-leadership and CD-helping / friendly axes had a stronger influence than the other four axes.

In the present study, due to the type of questions and the scoring method, some questions are reversely scored. No such cases were seen in our analysis of the results, because the data analysis method was different. To confirm the validity of the structure from EFA and CFA is used.

\section{Limitation of study}

One of the limitations of the study was the lengthy process of administration of the questionnaires due to the limitations of COVID-19 as the universities were closed. The questionnaires were distributed as had copy or as electronic form. This study was conducted on academic participants and, therefore, their international interactions can greatly reduce the existing cultural differences, which was one of the limitations of the study. Due to the time limitations and available sample during COVID-19 pandemic, EFA and CFA were performed on one the same sample group. However, CFA was done to complete the study. Therefore, CFA of this questionnaire with larger and different samples is recommended.

\section{Conclusion}

In conclusion, the Farsi version of QSDI with eight factors and 39 factors is a valid and reliable tool for Iranian society and it can be used for PhD and MSc students in medical sciences in Iran.

\section{Abbreviations}

MD: Medical Doctor; MSc: Master of Sciences; Ph.D.: Philosophiae Doctor; QSDI : Questionnaire on supervisor-doctoral student interaction; CVI: Content Validity Index; CVR: Content Validity Ratio; KMO: Kaiser Meyer Olkin; EFA: Exploratory Factor Analysis; CFA: Confirmatory Factor Analysis; TLI: Tucker-Lewis Index; NFI : Normed Fit Index; GFI: Goodness of Fit Index; RMSEA : Root Mean Square Error of Approximation; PC: Principal Components; SRMR: Standardized Root Mean Square Residual; KUMS: Kermanshah University of Medical Sciences

\section{Supplementary Information}

The online version contains supplementary material available at https://doi. org/10.1186/s12909-021-02932-0

Additional file 1: Annexed Table 1. Matrix of factor loads of the questionnaire questions on components after rotation. Annexed Table 2. Percentage of variance and eigenvalues of different factors

\section{Acknowledgements}

We are grateful to the Deputy for Research and Technology, Kermanshah University of Medical Sciences, for cooperating in this research. The authors would like to thank all the participants who patiently participated.

\section{Authors' contributions}

All authors participated and approved the study design. HD and AJ contributed to designing the study, AJ, HD, PA and EK collected the data, and data analyses were done by NS. The final report and article were written by $A J, P A$ and $H D$, and all authors read and approved the final manuscript. 


\section{Funding}

This study was drawn from a research project (No. 980786) sponsored by deputy of research and technology of KUMS. The cost of the payment is spent on the design and data collection of the study.

\section{Availability of data and materials}

The datasets used in the study are available from the corresponding author on reasonable request.

\section{Declarations}

Ethics approval and consent to participate

A written permission was secured from the developer of scale and the ethic committee of the Kermanshah university of medical sciences approved the study under the ethic code: IR.KUMS.REC.1398.897. All participants completed a written consent to participate in the study. In addition, the principles of Helsinki Declaration were observed.

\section{Consent for publication}

All participants consented verbally to publication of the interview data.

\section{Competing interests}

The authors declare that they have no competing interests.

\section{Author details}

'Department of Pediatrics, School of Medicine, Kermanshah University of Medical Sciences, Kermanshah, Iran. ${ }^{2}$ Substance Abuse Prevention Research Center, Research Institute for Health, Kermanshah University of Medical Sciences, Kermanshah, Iran. ${ }^{3}$ Student Research Committee, School of Nursing and Midwifery, Kermanshah University of Medical Sciences, Kermanshah, Iran. ${ }^{4}$ Department of Biostatistics, School of Public Health, Kermanshah University of Medical Sciences, Kermanshah, Iran. ${ }^{5}$ Department of Nursing, School of Nursing and Midwifery, Kermanshah University of Medical Sciences, Kermanshah, Iran.

Received: 15 October 2020 Accepted: 8 September 2021

Published online: 14 October 2021

\section{References}

1. Jensen $\mathrm{DH}$, Jetten J. Bridging and bonding interactions in higher education: social capital and students' academic and professional identity formation. Front Psychol. 2015;6:126

2. De Kleijn R, Meijer P, Pilot A, Brekelmans M. The relation between feedback perceptions and the supervisor-student relationship in master's thesis projects. Teach High Educ. 2014;19(4):336-49. https://doi.org/10.1080/13562 517.2013.860109.

3. Mhunpiew N. A Supervisor's roles for successful thesis and dissertation. US China Educ Rev 2013:3(2):119-122.

4. Hardman J. Tutor-student interaction in seminar teaching: implications for professional development. Act Learn High Educ. 2016;17(1):63-76. https:// doi.org/10.1177/1469787415616728.

5. Davis DF. Students' perceptions of supervisory qualities: what do students want? What do they believe they receive? Int J Dr Stud. 2019;14:431-64. https://doi.org/10.28945/4361

6. Ismail HM, Majid FA, Ismail IS. "It's complicated" Relationship: Research Students' Perspective on Doctoral Supervision Procedia - Social and Behavioral Sciences. Proc Soc Behav Sci. 2013;90:165-70. https://doi.org/10.1 016/j.sbspro.2013.07.078.

7. Doğan N, Bıkmaz Ö. Expectation of students from their thesis supervisor. Proc Soc Behav Sci. 2015;174:3730-7. https://doi.org/10.1016/j.sbspro.2015. 01.1106.

8. Heath T. A quantitative analysis of PhD students' views of supervision. Higher Educ Res Dev. 2002;1 (21):41-53. https://doi.org/10.1080/0729436022 0124648.

9. Garavand H, Kareshki H, Ahanchian M. The role of educational - research environment andsocial factors on the research self-efficacy of students of Mashhad University of Medical Sciences. J Med Educ Dev. 2014;8(4):32-46.

10. Aldrup K, Klusmann U, Lüdtke O, Göllner R, Trautwein U. Student misbehavior and teacher well-being: testing the mediating role of the teacher-student relationship. Learn Instr. 2018:58:126-36. https://doi.org/10.1 016/j.learninstruc.2018.05.006.
11. Lee $\mathrm{N}-J$. Professional doctorate supervision: exploring student and supervisor experiences. Nurse Educ Today. 2009;29(6):641-8. https://doi. org/10.1016/j.nedt.2009.02.004.

12. East $M$, Bitchener J, Basturkmen $H$. What constitutes effective feedback to postgraduate research students? The students' perspective. J Univ Teach Learn Pract. 2012;9(2)

13. Moskvicheva N, Bordovskaia N, Darinskaya L. Role of students and supervisors' interaction in research projects: expectations and evaluations. Proc Soc Behav Sci. 2015;171:576-83. https://doi.org/10.1016/j.sbspro.2015. 01.163 .

14. Abdullah MNLY, Evans T. The relationships between postgraduate research students' psychological attributes and their supervisors' supervision training. Proc Soc Behav Sci. 2012;31:788-93. https://doi.org/10.1016/j.sbspro.2 011.12.142.

15. Mainhard T, van der Rijst R, van Tartwijk J, Wubbels T. A model for the supervisor-doctoral student relationship. High Educ. 2009;58(3):359-73. https://doi.org/10.1007/s10734-009-9199-8.

16. Nutchrat $P$, Sumalee $C$. The validation of integrating teachers competency and participatory supervision model. Proc Soc Behav Sci. 2012;46:4626-31. https://doi.org/10.1016/j.sbspro.2012.06.309.

17. Wild D, Grove A, Martin M, Eremenco S, McElroy S, Verjee-Lorenz A, et al. Principles of good practice for the translation and cultural adaptation process for patient-reported outcomes (PRO) measures: report of the ISPOR task force for translation and cultural adaptation. Value Health. 2005:8(2):94104. https://doi.org/10.1111/j.1524-4733.2005.04054.x.

18. Polit DF, Beck CT, Owen SV. Is the CVI an acceptable indicator of content validity? Appraisal and recommendations. Res Nurs Health. 2007;30(4):45967. https://doi.org/10.1002/nur.20199.

19. Fonseca M. Principles and practice of structural equation modeling, third edition by Rex B. Kline Int Stat Rev. 2013;81(1):172-3. https://doi.org/1 0.1111 /insr.12011_25.

20. West SG, Finch JF, Curran PJ. Structural equation models with nonnormal variables: Problems and remedies. In: Structural equation modeling: Concepts, issues, and applications. Thousand Oaks, CA, US: Sage Publications, Inc; 1995. p. 56-75.

21. Parveen A, Roger W, Katie D. Postgraduate research students' and their supervisors' attitudes towards supervision. Int J Dr Stud. 2016:11:227-41.

22. Costello S, Benson J, Burns J, Bentley M, Elliott T, Kippen R. Adaptation and initial examination of the psychometric properties of the short supervisory relationship questionnaire (SSRQ) for use with general practice registrars. Educ Primary Care. 2020;31(6):1-8. https://doi.org/10.1080/14739879.2020.1 806114

23. Costello S, Kippen R, Burns J. Adapting the supervisory relationship measure for general medical practice. BMC Med Educ. 2018;18(1):284.

24. Henson R, Roberts JK. Use of exploratory factor analysis in published ResearchCommon errors and some comment on improved practice. Educ Psychol Meas. 2006;66(3):393-416. https://doi.org/10.1177/0013164405282485.

25. Watkins MW. Exploratory factor analysis: a guide to best practice. J Black Psychol. 2018;44(3):219-46. https://doi.org/10.1177/0095798418771807.

\section{Publisher's Note}

Springer Nature remains neutral with regard to jurisdictional claims in published maps and institutional affiliations.

Ready to submit your research? Choose BMC and benefit from:

- fast, convenient online submission

- thorough peer review by experienced researchers in your field

- rapid publication on acceptance

- support for research data, including large and complex data types

- gold Open Access which fosters wider collaboration and increased citations

- maximum visibility for your research: over $100 \mathrm{M}$ website views per year

At BMC, research is always in progress.

Learn more biomedcentral.com/submissions 